\title{
Correspondências temáticas entre Safo e a Odisseia
}

\author{
Josias Acencio ${ }^{\mathrm{i}}$
}

Resumo: O fragmento (31 L-P) da ode de Safo apresenta correspondências temáticas semelhantes às homéricas. Dessa forma, poderemos observar que Safo recorre a topoi homéricos em seus escritos. Abaixo, iremos observar esse fragmento, que foi preservado pelo autor do Peri Hýpsous, que, de acordo com Oliveira (2003), faz uma surpreendente reelaboração de topoi homéricos. Observaremos também (Odisseia IV, 705; XIX, 472) que tal fragmento, traz reações físicas como o mutismo, suor (Odisseia XX, 204) e pele esverdeada (Odisseia XI, 633; XXII, 42), que são os mesmos sintomas apresentados na ode da autora em questão. Poderemos observar que há uma interpretação correta a ser feita dessa poesia. O suporte para estabelecermos uma interpretação correta e confiável será obtido por meio de comentários de pesquisadores da área.

Palavras-chave: Rapsódia. Poesia. Ode. Homero. Safo.

\section{Thematic correspondences between Sappho and The Odyssey}

\begin{abstract}
The fragment thirty-one Lobel Page from Safo's ode show thematic correspondences similar to the Homeric ones. In this way we can observe that Safo scrutinize to Homeric topoi in her texts. Below we will see the fragment thirty-one Lobel Page from Safo's authorship, that was preserved by the Peri Hýpsous author, that according to Oliveira (2003) it is done a surprising relaboration to Homeric topoi. We will also see (Odyssey, IV,705; XIX,472) that the homeric text brings physical reactions as muteness, sweat (Odyssey, XX, 204), and green skin (Odyssey, XI, 633; XXII,42), the same symptoms showed at Safo's ode. We will observe that there is a correct interpretation to be done of this poetry. The support for us to establish a trustful and a correct interpretation will be taken from commentaries of researchers.
\end{abstract}

Keywords: Rhapsody. Poetry. Ode. Homer. Sappho.

Submetido em: 04 jun. 2018

Aprovado em: 19 nov. 2019

\author{
(cc) BY-sA \\ Esta obra está licenciada com uma Licença Creative Commons \\ Compartilha Igual 4.0 Internacional \\ DLCV - Língua, Linguística \& Literatura
}

\footnotetext{
${ }^{\mathrm{i}}$ Universidade Estadual de Campinas - Unicamp. E-mail: acencio.tradutor@hotmail.com.
} 
Fr. 31 Safo

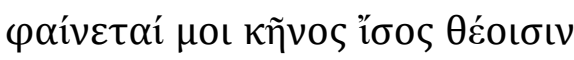

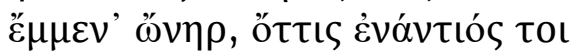

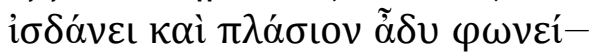

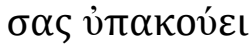

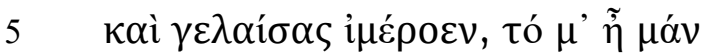

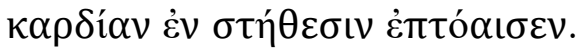

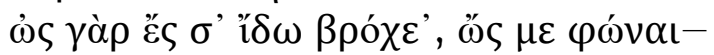

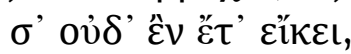

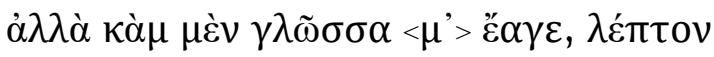

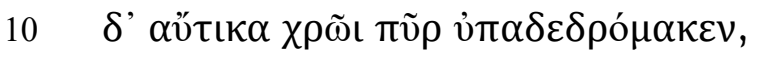

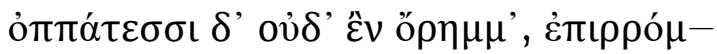

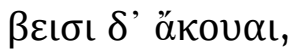

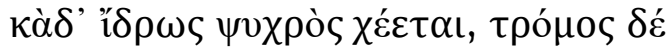

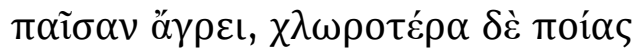

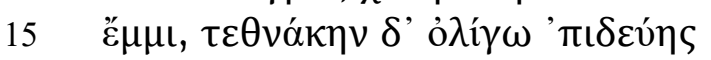

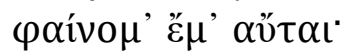

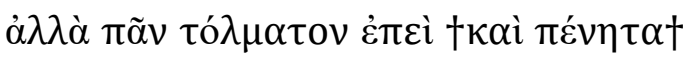

Parece-me ser igual a um deus quem a teu lado se senta e ouve de perto voz doce

e ledo riso que o brio no peito me turba:

fixo-te e já nada falo rompe-se-me a língua,

leve fogo sob a pele corre vela-me os olhos névoa, tonitruam-me os tímpanos,

suor invade-me gélido, toma-me toda tremor estou mais verde que grama, não estou vivo e nem morto e não sei nada. 
Odisseia IV, 705 (Mutismo)

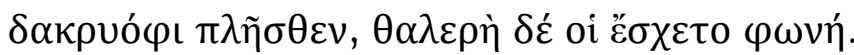

as lágrimas decaem do olhar, e, quase à tona, a voz aborta.

Odisseia XIX, 472 (Mutismo)

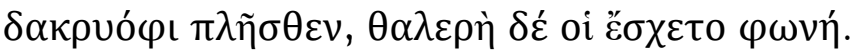

... marejam lágrimas, e a clara voz embarga.

Odisseia XX, 204 (Sudorese)

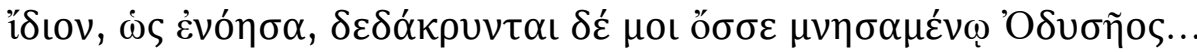

afluíram lágrimas nos olhos, ressudei em bicas ao te ver, pensando em Odisseu...

Odisseia XI, 633 (pele esverdeada)

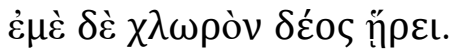

O medo esverdeado me domou.

Odisseia XXII, 42 (pele esverdeada)

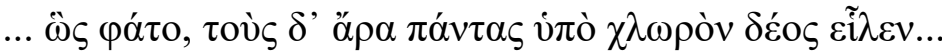

... O medo verde-cloro abate o bando em bloco... 
A Odisseia foi uma poesia desenvolvida numa época diferente da ode de Safo. O gênero textual também difere. A diferença fundamental entre esses dois poemas que vamos tratar aqui é a maneira e o motivo pelo qual são usados os sintomas que primeiramente aparecem em Homero na Ilíada e na Odisseia como sintomas de pesar, dor física, preocupação, pavor e tremor. Esses sintomas aparecem isolados, não juntos, como aparecem na poesia de Safo, o que é algo interessante, pois Safo introduz na poesia lírica o que Homero utiliza na poesia épica, enquanto a Ilíada e a Odisseia são poemas épicos em que a guerra e as implicações que ela traz fazem com que os homens sintam os mais diversos tipos de reações físicas. A ode de Safo é uma poesia de amor na qual ela descreve, com a precisão de uma médica legista, os sintomas que a tomam quando vê sua discípula conversando com um rapaz. Nos exemplos trazidos acima podemos observar isso.

Outra questão interessante é a interpretação que alguns leitores fazem dessa poesia. Estaria Safo, ao utilizar o pronome na primeira pessoa, falando de si mesma? Safo falava de seus sentimentos íntimos, ou o que ela cantava fazia parte de uma tradição poética da época? Para chegarmos a uma conclusão, devemos levar em consideração o que Bowra (1961, p. 7) nos diz a respeito do canto lírico oral.

Ainda que os poetas corais frequentemente falassem em primeira pessoa e não tivessem medo de expor suas opiniões, eles são menos íntimos e pessoais que os escritores do canto monódico, que falavam sem reserva de seus sentimentos mais íntimos e não se preocupavam em se identificar ou falar de alguém a não ser eles mesmos. ${ }^{1}$

De acordo com Bowra (1961), o fato de o poeta utilizar o pronome na primeira pessoa não garante que ele esteja falando do que é chamado na citação de: "sentimento mais íntimo do poeta". Miller (1994) ainda diz que o uso do pronome na primeira pessoa, utilizado no grego arcaico, não tem a mesma força que tem para nós como o nosso "eu”/“vós”. Segundo Miller (1994, p. 81), o eu é preferivelmente ligado à noção de comunidade, ou seja, não podemos afirmar que quando o/a poeta canta na primeira pessoa ele/ela esteja falando a respeito de seus sentimentos mais íntimos, mas de uma representação do grupo social da época, ideia essa defendida por alguns estudiosos como Havelock, Zumthor, Kurke e Thomas.

Calame (1977, p. 436, 438) reforça o que Miller diz a respeito do canto monódico. Ele afirma: “O 'Eu', no mundo do canto monódico, não significa, e de fato não pode significar, a

\footnotetext{
${ }^{1}$ Para obter uma perspectiva mais ampla sobre o uso dos pronomes pessoais nos cantos corais e monódicos, vide Bowra (1961). As traduções são minhas.
} 
opinião de um único indivíduo, mas antes é uma possível personificação da opinião que a comunidade compartilha." (CALAME, 1977, p. 438, tradução minha).

Tendo como base a afirmação desses pesquisadores, não podemos afirmar que o canto 31 L-P tenha sido de fato cantado de Safo para uma de suas discípulas como uma declaração de amor, nem que ela esteja falando de seus sentimentos íntimos. Antes de qualquer afirmação, devemos primeiro levar em consideração o que Calame (1977) diz na citação acima sobre o canto monódico.

O canto lírico oral que Safo cantava seguia os padrões da época, pois como Havelock (1982, p. 19) diz: “[...] a psicologia da composição não pode ser entendida dentro de limites colocados por pronomes pessoais." 2

Observemos agora a poesia de Homero em questão: a Odisseia. A Odisseia é um poema épico. Poemas épicos eram cantados para homenagear feitos heroicos. Podiam ser cantados ao fim das olimpíadas para o vencedor, no retorno de um herói para casa, vitória na guerra, dentre outros feitos. Como Finsler (1930, p. 10) nos diz:

A matéria mais primitiva da poesia épica é a lenda heróica, originariamente o canto épico surge do hino que se canta em uma festa de triunfo em honra a um herói de guerra, a um príncipe, a alguma realização importante que aconteceu naquele dia, dessa maneira o nome do herói celebrado não morre com ele, porém continua vivo nas canções. (FINSLER, 1930, p. 10). ${ }^{3}$

Dessa maneira, eram perpetuados os feitos do herói por meio das canções dos aedos, que realizavam suas performances com a finalidade de deixar para a posteridade as notáveis realizações dos homens.

Cantos épicos ou líricos, os aedos ou rapsodos eram contratados por um senhor que dava a eles pagamento pelo trabalho poético executado. Gentili (1996, p. 258) diz: “[...] e quando o tirano lhe ofereceu uma remuneração mais alta, ele compôs um epinício que começava engenhosamente com o verso: "saúde, filhas dos cavalos com pés de tormenta"".

Michael Schmidt indaga de forma interessante a respeito de quem Safo teria recebido a herança de cantar e usar termos já usados em poesias anteriores. Schmidt (2005, p. 174) nos diz: "[...] e sua própria configuração é diferente de alguma maneira da de seus contemporâneos e sucessores? É parte de sua sensibilidade como mulher? Ou simplesmente uma herança de Homero [...]?”.

\footnotetext{
${ }^{2}$ Para uma perspectiva diferente da apresentada por Calame e Havelock vide Thalmann, W. G. Conventions of Form and Thought in Early Greek Epic Poetry. Baltimore: Johns Hopikins University Press, 1984.

${ }^{3}$ Um estudo maior foi feito por Gentili, B. Poesía y Público en la Grecia Antigua. Tradução it.-es.: Xavier Riu. Barcelona: Quaderns Crema, 1996. Nessa obra, ele relata detalhadamente como se configurava o trabalho de 'ser aedo/ser cantor' na Grécia antiga.
} 
Não há autopiedade na estrutura textual dessa ode, mas o que Safo realmente tentava expressar na natureza dialógica desse poema, se comparado com Homero (Odisseia)? Levando em consideração a sutileza poética com que ela desenvolve seus poemas, em particular o fragmento analisado, sou tentado a acreditar que ao usar comparações temáticas iguais às usadas na épica de Homero (Odisseia) Safo deixa implícito ao leitor que o 'amor'4, de fato, também compreende uma épica em si, o que podemos observar pelos sintomas que são apresentados em ambos os poemas: Odisseia (Épica) e Fr. 31 L-P (Lírica).

Enfim, não importa a perspectiva com que observarmos essas comparações temáticas que vimos entre Homero (Odisseia) e Safo (Fr. 31 L-P). Elas são recorrentes; digo recorrentes sob a perspectiva de topoi poético.

\section{REFERÊNCIAS}

BOWRA, C. M. Greek melic poetry. Oxford: Oxford University Press, 1961.

CALAME, C. Les chœurs de jeunes filles en Grèce Archaïque, vol. 1. Rome: Edizioni Dell'Ateneo \& Bizarri, 1977.

FINSLER, G. La poesia homérica. Tradução de.-es.: Carlos Riba. Barcelona: Labor, 1930.

GENTILI, B. Poesía y público en la Grecia Antigua. Tradução it.-es.: Xavier Riu. Barcelona: Quaderns Crema, 1996.

HAVELOCK, E. A. The literate revolution in Greece and its cultural consequences. Princeton: Princeton University Press, 1982.

LONGINO. Libellus de sublimitate Fr. 31 L-P. Texto grego estabelecido a partir do fragmento $31 \mathrm{~L}-\mathrm{P}$. Disponível em: http://www.hsaugsburg.de/ harsch/graeca/Chronologia/S_ante06/Sappho/sap_me01.html. Acesso em: 02 jan. 2013.

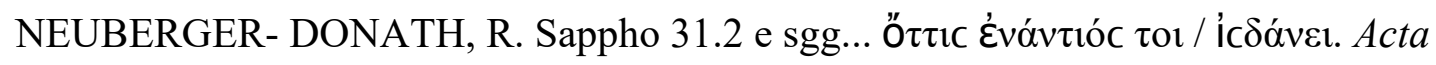
Classica, v. 20, p. 19-20, 1977.

MILLER, P. A. Lyric texts and lyric conciousness. London: Routledge, 1994.

OLIVEIRA, F. R. Revista Tradução Modelo 19, edição 14. Araraquara: Unesp, 2003.

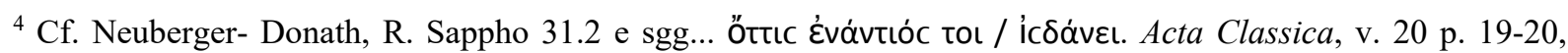
1977, para comparações temáticas nos poemas homéricos. A autora usa o termo 'philos' para descrever o que traduzi por amor.
} 
SCHMIDT, M. The first poets: lives of the ancient Greek poets. New York: Alfred A. Knopf, 2005.

VIEIRA, T. Odisseia. São Paulo: Editora 34, 2011. (Texto grego estabelecido a partir de Homer: Odyssey. Tradução: A. T. Murray, 1919; edição revista por George E. Dimock, Cambridge, MA; Londres, Harvard University Press, The Loeb Classical Library, 1998. Reproduzido em Perseus Digital Library: www.perseus.tufts.edu). 